DOI: 10.5748/9788599693148-15CONTECSI/PS-5650

A Gestão da Informação na Gestão da Inovação

Cláudio Roberto Magalhães Pessoa, http://orcid.org/0000-0002-9439-0382

(Universidade Fumec, Brasil) - cpessoa@ fumec.br

George Leal Jamil, http://orcid.org/0000-0003-0989-6600, (INESCTec, Portugal) gljamil@gmail.com

Armando Malheiro da Silva, http://orcid.org/0000-0003-0491-3758, (Universidade do

Porto, Portugal) - armando. malheiro@gmail.com

Marco Elísio Marques, http://orcid.org/0000-0003-1900-5509 (Universidade Fumec, Brasil) - marco.marques@fumec.br

\title{
Resumo
}

Inovar é uma condição Sine qua non para qualquer empresa que queira sobreviver no mercado dinâmico dos dias atuais. É importante conhecer as mudanças do mercado, as necessidades e expectativas de seus clientes, visando adequar seus produtos e/ou serviços à elas e, com isso, prestar um serviço de qualidade na busca de melhores resultados. Nesse intuito, é imprescindível adotar em sua estratégia a gestão da informação que forneça aos gestores a informação correta, no momento correto. Somente assim é possível inovar, criando soluções que atendam às demandas exatas.

Esse trabalho tem por objetivo apresentar como a gestão da informação se insere no contexto da gestão de inovação das organizações. Para tal, foi feita um estudo de múltiplos casos na área de engenharia. Apresenta um modelo teórico que auxilia os gestores na adoção de uma gestão de informações que levará a inovação nas organizações.

Palavras Chave: Gestão da Informação, Inovação, Gestão de conhecimento.

\section{Information Management in Innovation Management}

Innovating is a Sine qua non condition for any company survive in a dynamic marketplace like nowdays. It is important to know the market changes, the customers needs and expectations, aiming to tailor your products and / or services to them and, therefore, provide a quality service with better results. In this sense, it is essential to adopt one strategy an information management that provides to a managers the correct information at the right time. Only in this way is it possible to innovate, creating solutions that meet the market demands.

This paper aims to present how information management fits on the context of innovation management in organizations. For that, a multiple cases study, on engineering area, was made. It presents a theoretical model to assists managers to adopt an information management that will lead to innovation in organizations.

\section{Keywords: Information management, Innovation, Knowledge management}




\section{Introdução}

A inovação tornou-se obrigatória para que uma empresa sobrevida no mercado, sobretudo em momentos de crise. Segundo Drucker in Krames (2010), a maioria das empresas, em vias de regra, não obtêm êxito nos negócios, por ficarem presas a produtos e/ou serviços que foram sucesso no passado. Para Drucker, "os executivos que não conseguem descartar os negócios lucrativos do passado, apesar dos sinais crescentes de fracasso iminente, serão responsabilizados pela má execução do futuro". Apenas sabendo fazer o descarte de produtos/serviços ultrapassados a organização será capaz de inovar.

Mas, é comum, no momento que se fala em inovação, encontrar o pensamento de inovação ligado a invenção. Porém, essa afirmação não é verdadeira pois nem sempre inovar é criar algo novo.

É importante perceber as mudanças de mercado e necessidade dos clientes para obter sucesso, entregando exatamente que eles buscam. Para tal, gerenciar informações é imprescindível visando criar produtos e serviços inovadores.

\section{Referencial Teórico \\ Gestão de Inovação}

Pôde-se notar na bibliografia analisada que o marco do conceito de Inovação veio com a teoria de desenvolvimento de Joseph Schumpeter (1997) onde autor apresenta o seu conceito de "fluxo circular". Nesse conceito, a economia transcorre de forma natural e sem modificação; ou seja, todos os bens que são produzidos, serão consumidos.

Segundo Schumpeter (1997,pg.28) “o sistema econômico não se modificará arbitrariamente por iniciativa própria, mas estará sempre vinculado ao estado precedente dos negócios". É aí que surgem as inovações. Para que haja um crescimento econômico é necessário que algo novo aconteça e interrompa esse fluxo circular. Para o autor, essa inovação não acontecerá de fora para dentro, mas sim de dentro para fora. Segundo Schumpeter (2011, pg.74), entende-se por "desenvolvimento apenas as mudanças da vida econômica que não lhe forem impostas de fora, mas que surjam de dentro, por sua própria iniciativa". Essas inovações produzem mudanças de forma qualitativas e levam ao rompimento do "fluxo circular", consequentemente, levando a empresa a inovação. É importante situar que o conceito do autor foi desenvolvido no momento em que o mercado estava em processo de crescimento, onde a concorrência era pequena, ou quase nula, e existia, portanto, uma demanda reprimida. Com o passar do tempo, e a medida que o mercado cresceu e tornou-se competitivo, outras visões surgiram para inovação. 
Mais adiante no tempo, o conceito de inovação veio se adaptando com as mudanças que acontecem no mercado e nas organizações. Tomael, Alcará e Chiara (2005), baseadas em Barbieri (1997), afirmam que o conceito de inovação pode variar dependendo da área em que se estuda. Na área mercadológica é considerada qualquer modificação percebida pelo usuário, mesmo que não se faça nada que modifique fisicamente o produto. $\mathrm{Na}$ área de produção a inovação seria introduzir novidades materializadas em produtos, processos e serviços, novos ou modificados.

Em contraponto com Schumpeter, Drucker (1950), demonstra que com o crescimento da concorrência no mercado a preocupação dos gestores deve ser outra. Não é mais a empresa quem criará as inovações e as colocará para que o mercado as compre, mudando assim o ciclo dito por Schumpeter. Segundo ele, a concorrência acirrada dá ao cliente o poder de transformar o mercado, ou seja, é ele quem define o que compra e a qualidade do produto que pretende comprar.

Assim sendo, cabe às organizações conhecerem o seu cliente melhor para poder atender às suas expectativas. Para Drucker, o poder passou paras mãos do mercado. Conforme Drucker in Krames (2010), "o produto/serviço certo, para o cliente certo, com a distribuição adequada, por um preço adequado e no momento oportuno, fará os esforços de vendas a se reduzirem a quase nulo".

Nesse ponto, o conceito de inovação passa a estar ligado diretamente a Informação e conhecimento. Para alcançar o sucesso no "novo mercado" é necessário que as organizações conheçam bem as reais necessidades de seus clientes, buscando assim desenvolverem soluções inovadoras que as diferencie de seus concorrentes.

O Conceito de inovação tomou, portanto, um novo rumo. Conforme visto em Girole, Lima e Patah (2012, p. 618), inovar, nesse novo conceito, é "a criação de um novo conhecimento ou a combinação de saberes existentes que podem ser transformados em novos produtos ou processos que tenham valor econômico".

É necessário, portanto, conhecer os conceitos de gestão de informação para entender como utilizá-la na busca de inovação.

\section{Gestão da Informação}

Como visto anteriormente, gerenciar informação nas organizações tornou-se primordial para conhecer como atuar no mercado de forma inovadora. As organizações modernas têm como obrigação, no mercado competitivo em que atuam, conhecerem a fundo as necessidades de seus clientes na busca de diferencial competitivo. Caso isso seja possível, permitirá ao cliente sentir um diferencial no produto ou serviço adquirido. Importante lembrar que um dos principais critérios de qualidade na prestação de serviços, ou de produtos, será a imagem que o cliente faz daquilo que adquiriu.

Para tal, é mister conhecer os conceitos da gestão da informação que auxiliarão os gestores na inovação e, consequentemente, trarão o diferencial esperado.

No intuito de realizar uma gestão eficiente, é fundamental entender, em primeiro lugar, o ciclo informacional apresentado por Marchand, Kettinger e Rollins (2001) (Figura 1).

O propósito da gestão do ciclo da informação está na possibilidade de melhorar a forma como as informações são utilizadas na tomada de decisão dos gestores, pois elas só farão diferença na organização caso sejam utilizadas de forma eficaz nas tomadas de decisão. (MARCHAND, KETTINGER E ROLLINS, 2001)

$\mathrm{O}$ ciclo da informação inicia-se no momento em que se detecta uma necessidade de informação, ou seja, naquele momento em que se precisa, por exemplo, tomar uma decisão e não possui informações suficiente para embasá-la. Após a perceber essa necessidade, o gestor (ou profissional que tomará a decisão) buscará informações que o auxilie a solucionar o problema e tomar uma decisão mais precisa. 
Neste momento, é primordial, que o profissional de informação entenda como o usuário buscará a(s) informação(ões) necessária(s), e como é possível acessá-la(s). Isso permitirá selecionar as informações consideradas úteis e, por fim, buscá-las em fontes fidedignas, evitando com isso a coleta de informações irrelevantes que trariam uma perda de tempo e que ocupariam um espaço inútil nos sistemas de informação da organização. Segundo Marchand, Ketinger e Rollins (2001), a coleta de informações relevantes, além de evitar essa sobrecarga de informações, determinará também a forma como a empresa se organiza.

Após coleta, Alvarenga (2003) destaca a preocupação significante que deve existir no momento de entrar com os dados em um sistema de armazenamento e recuperação de informação. As informações devem ser classificadas, indexadas e focada nas necessidades dos usuários. Isso evita futuros problemas na sua recuperação, o que tornaria o sistema ineficiente.

Segundo Pessoa (2016), a classificação tem por objetivo, além da organização, a segurança das informações, pois somente assim poderá ser criada uma política de acesso às informações de acordo com as permissões dos usuários.

Após classificadas, as informações serão armazenadas em sistemas que, posteriormente, permitam serem recuperadas de forma eficaz, consequentemente, melhorando $\mathrm{o}$ embasamento nas tomadas de decisão.

A manutenção das informações será essencial, pois facilitará a sua utilização por parte do seu usuário. A correta manutenção economizará tempo e recursos, evitando informações irrelevantes, ou até mesmo uma recoleta de informações. E enfim o ciclo se fecha no momento em que o profissional faz o uso efetivo da informação.

Figura 1 - A gestão do ciclo informacional
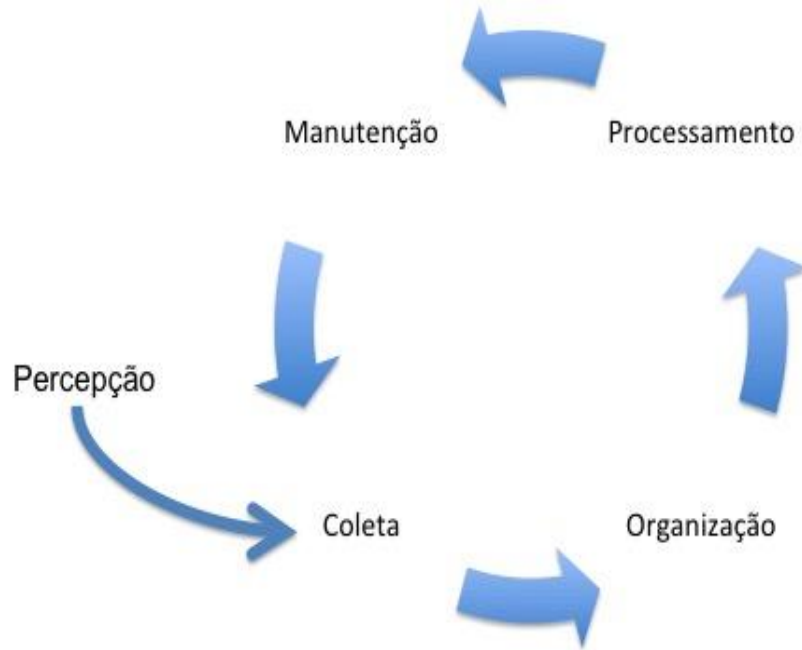

Fonte: Marchand, Ketinger e Rollins (2001, p. 76)

Segundo Tarapanoff

não se chega à inteligência pelo acesso passivo à informação. A inteligência deve ser criada, e é ao longo desse processo de criação, o processo da gestão da informação e do conhecimento, que se vai elaborando um sistema útil às organizações, integrado em sua cultura e em seus cenários voltados ao futuro. (TARAPANOFF, 2006: 31) 
Para a autora, a união do planejamento estratégico com gestão da informação, como interdependentes, possibilita uma convergência de ações que podem dar subsídios para a decisão estratégica.

Segundo Pessoa (2016), não basta somente gerir a informação, armazenando-a de forma correta, sem utilizá-la para o negócio da organização. É importante conhecer e gerenciar como os usuários a utilizam. Para colocar em prática essa ideia será apresentado a seguir um modelo que auxilia os gestores nessa tarefa.

\section{Modelo de Alinhamento da Gestão da Informação e do Conhecimento (MAGIC)}

O modelo MAGIC foi desenvolvido no intuito de auxiliar gestores a conhecer a gestão da informação que existe na organização e planejar uma implantação que a torne eficaz. Segundo Pessoa (2016), após as pesquisas realizadas em pequenas e médias empresas de engenharia no Brasil, percebeu-se a necessidade de mudar do foco da gestão nas empresas. Autores como Laurindo et al (2001), Lutchen (2003), Barba-Sánchez , Martínez-Ruiz e Jiménez-Zarco (2007), Pessoal e Jamil (2010) e Jamil (2014), mostram que os gestores de TIC investem mais em tecnologias, esquecendo de alinha-la às informações necessárias e ao negócio da organização. Para Drucker in Krames (2010), nos últimos 50 anos o foco das pesquisas, na área de TI (Tecnologia da Informação), estava concentrado na tecnologia. Segundo o autor é preciso agora focar todos os esforços na informação, que foi negligenciada todo esse tempo.

Nessa mudança de foco deve, portanto, segundo Pessoa et al (2016), primeiro analisar o negócio da organização para aí sim buscar às informações e adequar as ferramentas de TIC que irão suportá-lo.

O modelo MIAGIC, busca preencher a lacuna existente entre a gestão de informação e conhecimento com a área estratégica das organizações, auxiliando ainda na escolha correta das ferramentas de TIC que suportarão todas as tarefas e processos.

O modelo foi baseado nos modelos de Luftman (2000) e de OI de Marchand, Kettinger e Rollins (2001), cujo foco era a gerência e uso eficaz da informação e das TIC; e no modelo de Jamil (2014), onde foram criados critérios para análises de desempenho antes e depois da implantação. O modelo MAGIC (Figura 2) auxilia os gestores (sejam eles estratégicos ou de áreas técnicas, como TIC) a, primeiramente, conhecer e mensurar em qual nível se encontra a gestão da informação e do conhecimento na organização. Em seguida, após ter ciência da real situação, o modelo apresenta alternativas que visam atingir um nível maior de alinhamento, o que, consequentemente, poderá trazer melhores resultados para organização. 


\section{Figura 2- Modelo de Alinhamento de Gestão da Informação e do Conhecimento (MAGIC)}

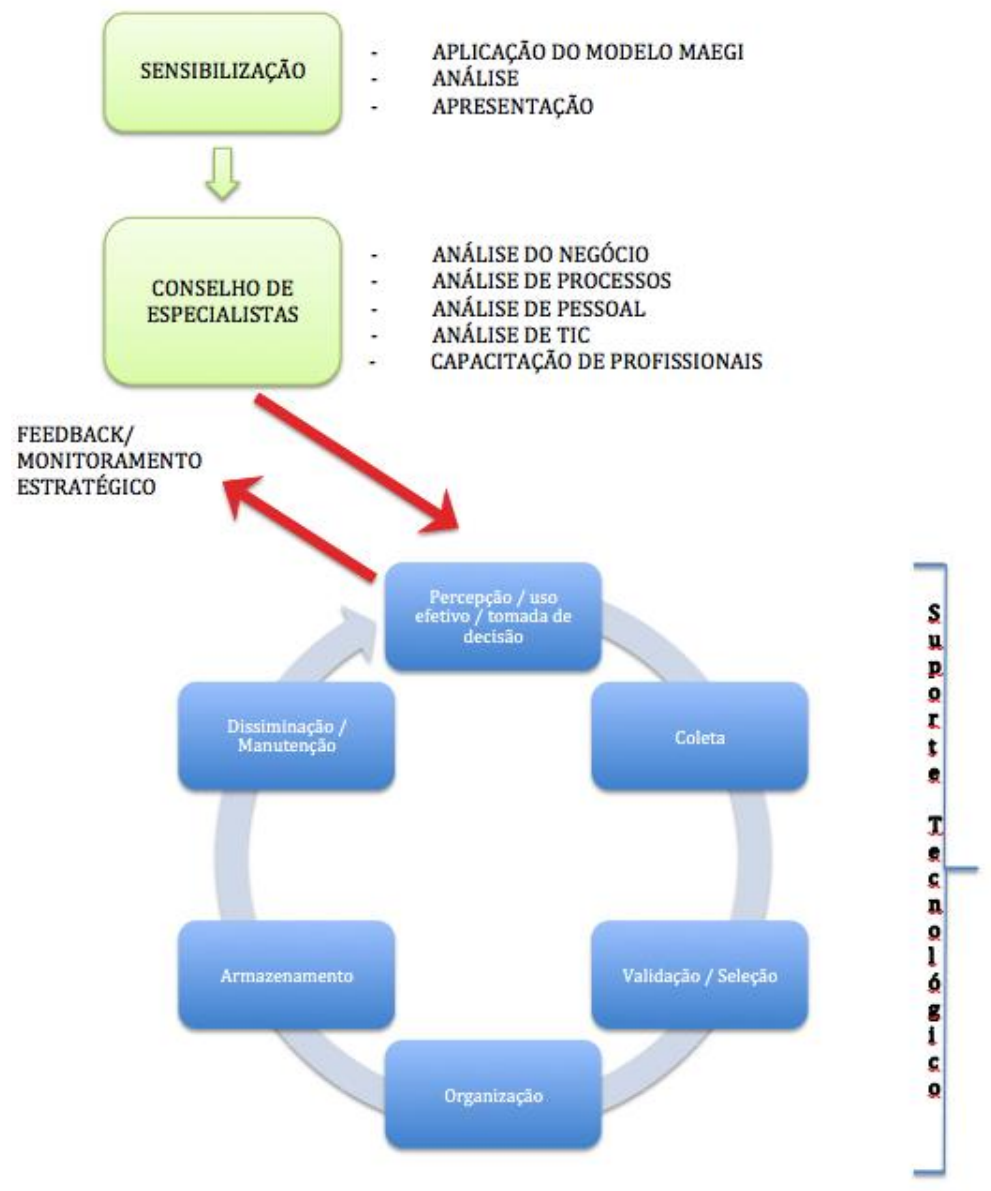

Fonte: Pessoa (2016)

Para melhor entendimento, o modelo foi dividido em etapas que permitem um zelo maior na explanação e adaptá-lo à realidade de cada organização, uma vez que a análise inicial poderá levar a resultados diferentes em empresas diferentes.

\section{Etapa 1 - Sensibilização}

$\mathrm{Na}$ fase de sensibilização é aplicado o modelo MAEGI (Modelo de alinhamento estratégico e gestão da Informação e do conhecimento) (Figura 3), que permitirá aos gestores, no início, conhecerem em qual nível se encontra a gestão da informação em relação ao alinhamento com a estratégia da organização e as ferramentas de TIC existente.

O modelo parte da necessidade de, além de conhecer a organização, sensibilizar os gestores a investirem em uma gestão da informação, que alinhe as ferramentas de TIC às tomadas de decisão estratégica.

É importante, para uma elaboração do plano estratégico, conhecer a atual situação da organização. Caso contrário corre-se o risco de, ao final, não existirem parâmetros de comparação para mensurar uma possível melhoria dos resultados obtidos.

O modelo MAEGI, assim como o modelo de Luftman (2000) e da visão de Porter (1986), parte do princípio de que toda empresa possui, ainda que em nível mínimo, um grau de alinhamento estratégico entre a gestão da informação e o negócio da organização. O modelo utiliza, como critérios de análise do nível de alinhamento, as três capacidades de informações básicas do modelo OI de Marchand, Kettinger e 
Rollins (2001), bem como os critérios de governança dos setores de TIC e gestão do modelo de Luftman. Com isso, permite ao gestor ter uma visão ampla do foco dado pela organização na busca de melhor resultado operacional. Ademais, permite criar critérios que levem a organização a níveis mais altos do alinhamento estratégico. As pesquisas de Pessoa et al (2016) e Pessoa (2016) demonstraram ser o modelo MAEGI eficiente para atingir objetivo proposto. Nas entrevistas realizadas nas empresas de engenharia mostrou que, as empresas pesquisadas, estão classificadas no nível 1 e 2 do modelo MAEGI. Isso porque todas elas mostraram haver um interesse por parte da gestão em alinhar as informações, mas só fazem alguma coisa nesse sentido quando organizam e armazenam documentos ligados às normas técnicas com ISO9001.

Foi possível perceber também que os diretores, no momento das entrevistas, se sensibilizaram da importância em se adotar uma gestão eficiente da informação e conhecimento em suas organizações. Daí o fato da primeira etapa ser nomeada de Sensibilização.

Essa etapa (Sensibilização) é de fundamental, pois é baseado nela que serão criados parâmetros e métricas que apontarão a melhoria (ou não) dos resultados operacionais após adoção do modelo, que foi um dos maiores problemas detectados por Pessoa (2016). Sem parâmetros iniciais, por mais que haja uma melhoria, não há critérios que comprovem, tornando assim a gestão intuitiva e não profissional. 


\section{Figura 3: Modelo de alinhamento estratégico e Gestão da informação e do conhecimento (MAEGI)}

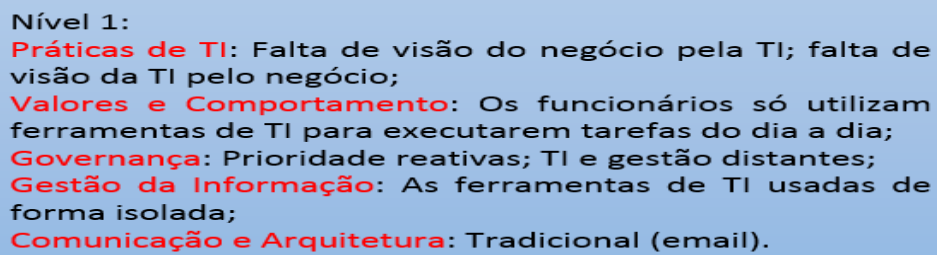

\section{Fonte: Pessoa (2016, pg 71)}

\section{Etapa 2 - Conselho de Especialistas}

A segunda etapa é de fundamental importância em relação ao negócio da organização. De posse das informações coletadas na etapa 1, é necessário conhecer as ferramentas e práticas de TIC, as pessoas envolvidas e os processos de negócio. Tripé essencial para uma gestão de qualidade. O foco dessa etapa está na gestão estratégica da organização. É aqui que será feito planejamento necessário para traçar objetivos e escolher os recursos que permitirão alcança-los. Essa etapa foi nomeada, no modelo, de Conselho de Especialistas e baseia-se nos conceitos da teoria da agência (JENSEN; MECKLING, 1976).

Segundo Monsma (2000, pg. 84), a teoria da agência "permite identificar problemas e contradições centrais nas relações entre principal e agentes e ajuda a entender porque 
certas soluções são eficazes, mas não suficiente para explicar os arranjos específicos que se adotam na prática". O autor destaca que a teoria da agencia está focada na "escolha racional", onde, dentro de uma gama de opções, escolhe aquela que irá maximizar os resultados organizacionais.

Portanto, o Conselho deve ser composto por diretor(es) da organização e profissionais externos de notório saber em áreas que complementem o conhecimento interno. $\mathrm{O}$ Conselho terá a função de prestar consultoria ao negócio da organização. A função básica da gestão é o controle, que, por sua vez, tem por finalidade "assegurar que os resultados do que foi planejado, organizado e dirigido se ajustem, tanto quanto possível, aos objetivos previamente estabelecidos" (CHIAVENATO, 2003, p. 176). Com esta visão, a função do conselho de especialistas, nessa etapa, será:

- Análise do negócio: É de extrema importância que o conselho obtenha, junto aos gestores, um conhecimento profundo do negócio da organização, procurando se aprofundar nas necessidades, estratégias, custos, objetivo, missão, etc.;

- Analisar processos: O conselho deverá mapear todos os processos existentes, encontrar possíveis falhas nesses processos, detectar processos que deveriam existir e fazer um redesenho dos processos que visem a atender às necessidades da organização;

- Análise de pessoal: Também é de fundamental importância conhecer os profissionais envolvidos com a empresa, visando a fazer um gerenciamento por competência, alinhando às necessidades da organização e da gestão estratégica que se propõe;

- Análise de TIC: Analisar todas as ferramentas existentes, bem como as soluções adotadas, visando a alinhá-las às necessidades do negócio da organização. Este aspecto será melhor detalhado na próxima parte do modelo;

- Capacitação de profissionais: essa função tem por objetivo capacitar profissionais internos, analisados na etapa anterior, em conjunto com os diretores, para que possam dar continuidade ao trabalho implantado. Não é intenção que a consultoria se perpetue, sendo a sua atuação pontual. O Conselho de Especialistas dará um apoio posterior aos profissionais capacitados e aos gestores para soluções futuras, participando de reuniões estratégicas convocadas pelos gestores, caso julguem necessário.

Atento aos riscos da terceirização de serviços (consultoria), torna-se interessante o modelo apresentado nesse trabalho, onde o Conselho de Especialistas aparece como aliado da organização (cliente), por possuir profissionais de diversas áreas de conhecimento, o que possibilita uma discussão interdisciplinar, trazendo um ganho qualitativo às tomadas decisões do negócio da organização. Outro fator importante a ser levado em consideração é o tempo de prestação de serviço, pois poderá tornar a empresa contratante em "refém" do provedor, o que o tornaria vulnerável.

No caso do Conselho de Especialistas (indicado), acontecerá uma atuação controlada, ou seja, com tempo definido para início e fim da intervenção externa (consultoria). Após este período, caso seja de interesse da organização, o Conselho poderá participar de reuniões estratégicas, esporadicamente, visando auxiliar os gestores nas tomadas de decisão futuras. Com isso a parceria tornar-se-á vantajosa e trará melhores resultados.

No modelo MAGIC, é de suma importância a organização criar uma cultura de gestão da informação e do conhecimento, cujos valores e ações visam o desenvolvimento dessa prática na organização. Destarte, torna-se imprescindível um plano de capacitação e avaliação contínuo na organização, no intuito de aprimorar sempre esse aspecto. 


\section{Etapa 3 - Gestão da Informação e do Conhecimento}

$\mathrm{Na}$ etapa 3, é dada uma atenção especial ao ciclo da informação, que conforme autores como Choo (2003), Silva (2006), Silva e Ribeiro (2009), Barbosa e Nassif (2012), Estrela (2014), Jamil (2014), o cerne da gestão da informação e do conhecimento. O modelo MAGIC traz um avanço em relação ao modelo de Marchand, Kettinger e Rollins (2001) apresentado anteriormente, a saber:

Percepção: O ciclo, para gestão da informação (assim como visto na figura 1), inicia-se no momento em que o gestor, no momento que precisa tomar uma decisão, sente a necessidade de buscar mais informações sobre o que se está analisado, para estudar alternativas e, efetivamente, tomar sua decisão.

Coleta: Nessa fase, segundo Jamil (2014), acontece a função de angariar, coletar e gerar informações e conhecimento. É fundamental entender onde buscar informações pertinentes às necessidades de cada usuário.

Validação / Seleção: Essa é uma fase adicionada ao modelo original. Logo após coletadas as informações, é preciso validá-las junto aos usuários da informação. É importante destacar que o advento da internet e das redes sociais fez com que a busca e coleta da informação ficasse mais ágil. Porém, como visto em Silva e Ribeiro (2009), o excesso de informações exige formas inteligentes e eficientes de tratamento que permitem localizar, identificar e rentabilizar ao máximo o uso das mesmas. Não será proveitoso para a organização obter um excesso de informações e armazená-las se, no momento do seu uso efetivo, essas informações não forem precisas nem atendam às necessidades dos gestores e da organização.

Para Moresi (2001), a informação tem as finalidades de conhecimento dos ambientes interno e externo de uma organização e auxiliam a organização a atuar nesses ambientes. Assim, devem ser classificadas segundo o nível de importância que elas terão no desempenho do negócio. Segundo o autor, os níveis encontram-se figura 4. De acordo com Moresi (2001), as organizações devem manter o seu esforço na busca de informações crítica, mínimas e em potencial, nesta ordem. As informações sem interesse devem ser reconhecidas, para que se evite esforça de coleta.

\section{Figura 4: Classificação da Informação}

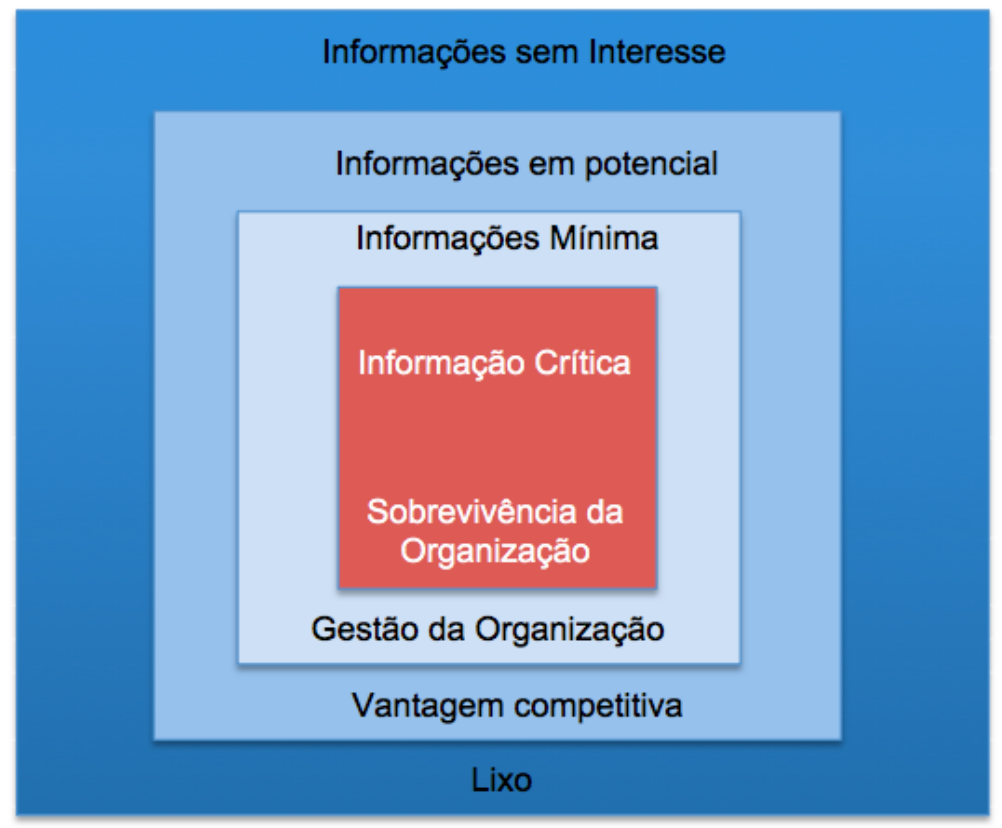

Fonte: Moresi (2015) 
Organização: Após seleção e validação das informações, surge a necessidade de organização. Neste ponto, é importante relembrar o que foi dito por Alvarenga (2003). A implantação de um sistema de GI eficaz deve recorrer a três estágios: a) Estágio anterior à entrada de itens no sistema de informação; b) estágio que corresponde à entrada do item no sistema; c) estágio pós-inclusão do item no sistema. Todo este cuidado visa a uma recuperação eficaz, que permita a aplicação conforme esperado. Uma preocupação significante está no momento de entrada dos dados, pois a classificação desta informação (sua organização e indexação) torna-se primordial, sob pena de, posteriormente, não se conseguir recuperar a informação desejada.

Armazenamento: Nessa fase da gestão da informação, serão analisadas as melhores soluções de TIC que atendam a demanda. Nesse momento, o conceito do modelo SI-AP, de Silva e Ribeiro (2009), ganha importância ao lembrar que "a noção estática e analógica de documento (conteúdo + qualquer suporte material) é subordinada à noção operatória da informação". Segundo os autores, nem toda informação está hoje no formato eletrônico, "como a panaceia da adoção entusiástica e ingênua de ferramentas de TIC fez crer que fosse". Muitas informações podem estar em papéis, e até mesmo com as pessoas que as detêm. E não podem ser perdidas ou até mesmos substituídas, pois fazem parte de um histórico fundamental para o aprendizado organizacional. É importante, portanto, criar uma solução que consiga armazenar, de forma ativa e permanente, essas informações.

Disseminação/Manutenção: Segundo Jamil (2014), essa fase avalia as formas de distribuir e dar pleno acesso aos acervos, para os interessados. A disseminação e a manutenção da informação ganham importância quando o assunto do conhecimento é tratado. Diversos autores, como Marchand, Kettinger e Rollins (2001), Capurro (2003) e Freire (2006) chamam a atenção para esse fato.

A gestão do conhecimento é composta pelas atividades e processos de encontrar conhecimento existente em uma organização, sistematizar e organizá-lo para disponibilizá-lo para toda a organização, suportado por ferramentas de TIC. Para Marchand, Kettinger e Rollins (2001) e Capurro (2003), o conhecimento só será útil caso seja compartilhado.

Por isso, é de suma importância que seja analisada, no momento da análise do negócio, quais são as reais demandas da organização, quais são as informações que serão necessárias armazenar para, aí sim, determinar as ferramentas de TIC que suportarão toda a solução. Essa escolha está ligada à quarta fase do modelo.

Uso Efetivo/Tomada de Decisão: como foi visto, o fim do ciclo da informação terminará no momento em que os gestores, utilizando as informações e conhecimento adquiridos, tomam a decisão baseados nas alternativas listadas. Escolhem, dessa forma, aquela que lhes parecer mais favorável à organização, o que Monsma (2000) e Choo (2003) chamaram de escolha racional.

Feedback/Monitoramento Estratégico: Essa etapa também foi acrescentada ao modelo original. Segundo Jamil (2014, p. 22), apud Almeida et al. (2014), o feedback, chamado por Jamil de valorização, "destina-se a estudar e apreciar os métodos quantitativos aplicados e as tentativas de apropriar valores financeiros e de outras grandezas relacionadas a indicadores, como produtividade, custo de oferta, preços, etc.", e o monitoramento estratégico "se destina a perceber se a informação e conhecimento gerados poderiam ser aplicados para finalidades estratégicas, como tomadas de decisão e planejamento".

Essa fase é importante para o negócio, no que diz respeito à gestão estratégica. Assim como na etapa de sensibilização, é importante conhecer a situação da empresa, no início 
do processo, criando indicadores e traçando metas a serem atingidas. Neste momento será necessário, novamente, avaliar esses indicadores, visando a comparar o resultado antes e após a implantação do método. Com os resultados, é possível saber se a organização atingiu as metas traçadas, se houve melhoria (ou não) dos indicadores analisados, se o nível do alinhamento estratégico da gestão da informação e conhecimento com o negócio da organização aumentou, e se as soluções de TIC estão suportando o negócio como deveriam. Com essas informações, é possível traçar novas metas, criar novos produtos e planejar novas melhorias para o negócio da organização.

\section{Etapa 4 - Suporte Tecnológico}

Essa etapa aborda as soluções em TIC que suportarão todo o processo. As tecnologias têm uma grande parcela de contribuição para uma implantação e manutenção, bem sucedida, da gestão proposta.

É importante, porém, ressaltar mais uma vez, a inversão de prioridades no momento de elaborar a gestão. Como fica claro no modelo, primeiro, deve-se estudar o negócio, em conjunto com as necessidades do uso da informação e do conhecimento gerado, para só então escolher as ferramentas de TIC que suportarão toda a gestão.

Segundo Jamil e Silva (2014), é necessário um estudo mais aprofundado, visando a permitir a utilização de toda essa infraestrutura que possibilite atingir os objetivos traçados na estratégia da organização.

As ferramentas de TIC suportam a gestão da informação e do conhecimento, porém, conforme é visto em Pessoa e Jamil (2010), é importante lembrar que os profissionais devem possuir conhecimento necessário na gestão da informação e, por fim, das tecnologias que se adequem melhor a esse objetivo. Não se pode escolher a solução de TIC para depois implantar os processos. É primordial que, em primeiro lugar, conheçam-se as estratégias, os processos e as pessoas envolvidas, para, enfim, escolher a melhor tecnologia que atenda a essas necessidades. Para tal, além do gestor de TIC possuir esse conhecimento, é primordial que ele participe do planejamento estratégico da organização e as pesquisas realizadas mostram que isso não é uma realidade das organizações. (Pessoa e Jamil, 2010) e (Pessoa, 2016)

Uma alternativa de modelo que auxilie os gestores de TIC na adoção de soluções alinhadas ao negócio é o modelo de Engenharia de Requisitos (ER). Segundo Kotonya e Sommerville (1998), ER é uma ferramenta que tem o objetivo de analisar as atividades envolvidas na descoberta, documentação e manutenção de um conjunto de requisitos para um sistema baseado em computadores.

Segundo Rocha (2000), a Engenharia de Requisitos é a etapa inicial para se desenvolver um sistema, em que o "engenheiro de requisitos" (profissional responsável por elaborar o sistema), em contato com os profissionais que irão utilizar o sistema, busca levantar o maior número de informações possível, a fim de que o sistema funcione e atenda as expectativas da organização. Segundo o autor, a adoção de novos sistemas, principalmente os TIC, afeta os arranjos organizacionais e os sistemas de informação.

Portanto, é importante analisar esses aspectos, visando a entender e definir os processos básicos, as necessidades requeridas pela organização e definir bem os requisitos do sistema, de forma que atenda as necessidades da organização. É mister salientar que o sistema de requisitos auxiliará o responsável pela sua elaboração a conhecer e definir as soluções que atendam as necessidades da organização, antes da escolha da solução tecnológica, conforme discutido anteriormente. Portanto, baseado em Rocha (2000), as etapas de um processo de Engenharia de requisitos (FIGURA 5) são:

Obtenção/definição: Essa etapa busca conhecer os requisitos necessários para implantação de soluções. Existe uma interação do(s) responsável(veis), que é feita 
por meio de consulta aos utilizadores, documentos existentes de sistemas legados, conhecimento da abrangência da solução, análise das necessidades da organização e, se possível, análise de necessidades do mercado. Para Franceto (2005), existem várias técnicas conhecidas para atingir esse objetivo: entrevistas, prototipações, pontos de vista, cenários, casos de uso, etc.

Análise e negociação: de posse dos requisitos levantados, analisam-se todos, em conjunto com os utilizadores, visando a negociar aqueles passíveis de implantação, e ainda, quais devem ser modelados (modificados), para que seja viável a sua implantação. É necessário, nessa etapa, cruzar os requisitos de setores diferentes, buscando negociar com as partes envolvidas a melhor solução para a organização.

Documentação: Todos os requisitos serão então modelados e documentados de forma que sejam compreendidos por todos os interessados. Segundo Rocha (2000), essa documentação deve ser feita em linguagem gráfica de fácil entendimento.

Validação: Essa etapa visa a analisar a documentação elaborada, em conjunto com as partes envolvidas, antes de serem utilizadas para escolha da solução final. Visa a corrigir possíveis problemas que, por algum motivo, podem ter passado desapercebidos. Essa etapa deverá se repetir até que a documentação dos requisitos seja validada e aceita por todos os envolvidos.

Implantação: Nessa etapa, implanta-se a solução, seguindo os requisitos modelados e documentados.

Análise das mudanças: Nessa etapa, os responsáveis pela implantação deverão analisar se as soluções adotadas surtiram o efeito necessário para atender os requisitos do sistema e de seus usuários. Como consequência, se atendeu as necessidades do negócio. Além disso, é importante criar uma rotina de avaliação contínua dos ambientes, interno e externo da organização, visando a possíveis correções das soluções adotadas e, até mesmo, a adoção de novas soluções que complementem ou substituam as que estão em vigor.

\section{Figura 5 - Ciclo da Análise de Requisitos para implantação de Sistemas de}

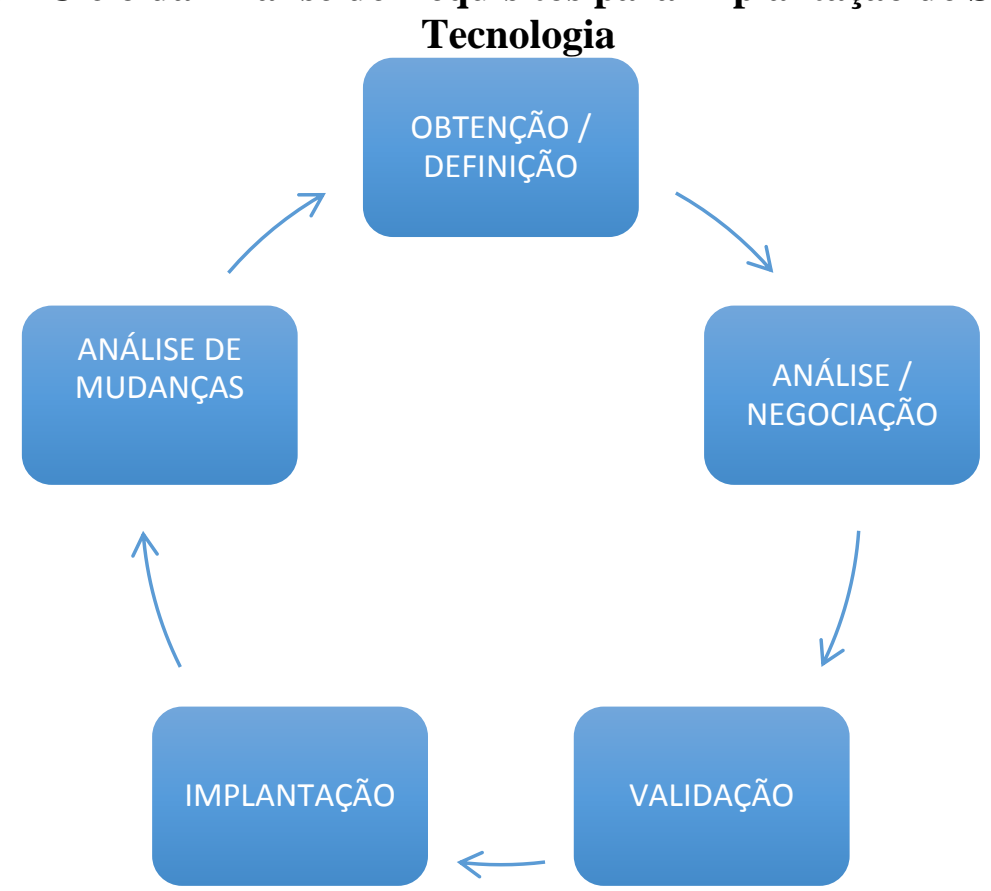

Fonte: Adaptado de Kotonya e Sommerville (1998), Rocha (2000) e Franceto (2005).ao 
Com isso fecha-se o ciclo do modelo e toda atividade deverá ser avaliada e inicia-se o ciclo novamente.

\section{Considerações Finais}

Conforme visto ao longo do texto, o mercado atual exige das organizações um conhecimento profundo em relação ao mercado no qual estão inseridas. Somente desta forma será possível criar inovações que darão a elas um diferencial competitivo que lhe permita avançar no mercado. Foi possível perceber que a inovação depende sensivelmente da gestão da informação. Não é possível atualmente gerar inovações sem conhecer bem a empresa, os clientes e o mercado.

O modelo MAGIC, apresentado nesse trabalho, dá aos gestores conhecimento sobre as falhas dos processos de gestão da informação, permitindo corrigi-las e adotar uma gestão que alinhará a estratégia do negócio, as informações e as ferramentas de TIC, que suportarão todo o processo. O modelo se mostrou eficaz nas entrevistas realizadas em Pessoa (2016) e foi possível perceber uma falta de alinhamento estratégico nas empresas pesquisadas.

Após análise inicial, e seguido os passos do modelo, busca-se uma implantação eficaz. É importante o gestor, depois de implantar o modelo, reiniciar o processo de análise, utilizando o modelo MAEGI, que possibilitará nesse momento conhecer qual foi o nível de melhora da orientação da informação em relação ao negócio da organização.

Somente assim as organizações poderão competir no mercado de forma mais competitiva, uma vez que as tomadas de decisão, principalmente na área estratégica, estarão baseadas em informações precisas, permitindo com isso que o gestor as tome de forma mais consciente.

O foco dos estudos em questão foram as pequenas e médias empresas da área de engenharia. Como trabalhos futuros é interessante a aplicação do modelo em áreas diferentes da engenharia e empresas de maior porte; e até mesmo aumentar o número de empresas pesquisadas visando montar um perfil do alinhamento da gestão de informação com o negócio das organizações no Brasil.

\section{Referências}

ALVARENGA, L. Representação do Conhecimento na Perspecitva da Ciência da Informação em Tempo e Espaço Digital. Universidade Federal de Minas Gerais, Brasil. 2003

ANSOFF, H. I.; DECLERCK, R. P.; HAYES, R. L. Do planejamento estratégico à adminis- tração estratégica. São Paulo: Atlas, 1981.

BARBOSA, R. R.; NASSIF, M. E. Práticas de Gestão e de Tecnologia da Informação e seu rela- cionamento com o desempenho organizacional. Perspectivas em Gestão, Conhecimento, João Pessoa, v. 2, Número Especial, p. 104-117, out. 2012. http://periodicos.ufpb.br/ojs2/index. php/pgc. ISSN: 2236-417X.

BELFORT, J. Consultoria Empresarial: a função do consultor nas empresas. Presença Revista de Educação, Cultura e Meio Ambiente, [S. 1.], v. 8, n. 28, maio 2004. Disponível em: <http://tupi. sica.ufmg.br/michel/docs/Artigos_e_textos/Gestao/consultoria_empresarial. pdf $>$. Acesso em: 15 jan. 2016.

BRADLEY, K. Intellectual capital and the new wealth of nations II. Business Strategy Review, v.8, n. 4, p. 33-44, 1997.

CAPURRO, R. Epistemologia y Ciencia de la Información. In: ENCONTRO 
NACIONAL DE PESQUISA EM CIÊNCIA DA INFORMAÇÃO, 5., 2003, Belo Horizonte. Anais... Belo Horizonte: Escola de Ciência da Informação da UFMG, 2003. Disponível em: <http://www. capurro.de/enancib.htm>. Acesso em: 03 mar. 2014. Conferência.

CHIAVENATO, Idalberto. Introdução à teoria geral da administração. Rio de Janeiro: Campus, 2003.

CHOO, C. W. A organização do conhecimento: como as organizações usam a informação para criar signi cado, construir conhecimento e tomar decisões. Tradução de Eliana Rocha. São Paulo: Editora Senac São Paulo, 2003.

Costa A. B. da. O desenvolvimento econômico na visão de Joseph Scumpeter. Uninsinos, ano $4-\mathrm{n}^{\circ} 47-2006$

DAVENPORT, T. Ecologia da Informação. São Paulo: Futura, 1998.

DRUCKER P. F. e age of discontinuity: guidelines to our changing society. Harper and Row Publishers, 1969.

ESTRELA, S. C. L. A Gestão da Informação na Tomada de Decisão das PME da Região Centro: um estudo exploratório e de multicasos no âmbito da Ciência da Informação. 2014. 451 f. Tese (Doutoramento em Letras, Área de Ciência da Informação Arquivística e Biblio- teconômica - Especialidade de Teoria e Metodologia de Estudo e Organização da Infor- mação Arquivística e Biblioteconômica) Universidade de Coimbra, Coimbra, 2014a.

FREIRE, G. H. Ciência da Informação: temática, histórias e fundamentos. Perspectivas em Ciência da Informação, Belo Horizonte, v. 11, n. 1, p. 6-19, jan./abr. 2006.

JAMIL, G. L. Gestão da Informação e do Conhecimento em empresas brasileiras: estudo de múltiplos casos. Universidade Federal de Minas Gerais: Escola de Ciência da Informação, tese de Doutorado, aprovada em 01/06/2005. Disponível em http://www.bibliotecadigital. ufmg.br/dspace/bitstream/handle/1843/VALA6KHGGG/doutorado__george_leal_jamil.pdf?sequence $=1$, com acesso em setembro de 2012.

JAMIL, G. L.; SILVA, A. M. Estruturação de O cina de Inteligência de Mercado. In: AlMEIDA, A. S. de A.; SILVA, A. M.; FRANCO, M. J. B.; FREITAS, C. C. de. Coletânea Luso- Brasileira V - Gestão da Informação, Cooperação em redes e Competitividade. Porto: Universidade do Porto, 2014.

JENSEN, M. C.; MECKLING, W. eory of Firm: Managerial Behavior, Agency Cost and Ownership Structure. Journal of Financial Economics, [S. 1.], v. 3, p. 305-360, 1976.

Krames, J. A. A cabeça de Peter Drucker, Sextante. Rio de Janeiro, 2010

LUFTMAN, J. Assessing Business-IT Alignment Maturity. Communications of the Assso- ciation for Information Systems, [S. 1.], v. 4, Dec. 2000. Article 14. Disponível em: 〈http:// www.itu.dk/courses/SBIT/E2008/IT-Business\%20Alignment_lu man.pdf>. Acesso em: 10 jun. 2009.

KATZ, R. L. Cases and Concepts in Corporate Strategy. New Jersey: Prentice-Hall Inc, 1970. KOTONYA, P.; SOMMERVILLE, I. Requirements Engineering: Processes and Techniques.

Hoboken, NJ: John Wiley, Sons Ltd, 1998.

KOTLER, P.; KARTAJAYA, H.; SETIAWAN, I. Marketing 3.0: as forças que estão de nindo o novo marketing centrado no ser humano. Rio de Janeiro: Elsevier, 2010.

MARCH, J.G. O processo decisório nas organizações. In: PUGH, Derek S.; HICKSON, David J. Os teóricos das organizações. Tradução de Afrânio Carvalho Aguiar et al. Rio de Janeiro: Qualitymark, 2004. p.143-148.

MARCHAND, D. A.; KETINGER, W. J.; ROLLINS, J.D. Information Orientation: e 
Link to Business Performance. Oxford University Press. 2001

Martins, P. S.; Alves, L. H. D.; Plonski, G. A. Gestão de Inovação: Uma análise da utilização de ferramentas pelas empresas. ALTEC - USP, 2013

MINTZBERG, H. Strategy-Making in ree Modes. In: MINTZBERG, H.; QUINN, James Brian; JAMES R. M. (Ed.). e Strategy Process: concepts and contexts, and cases. Engle- wood Cli s, NJ: Prentice Hall, 1988.

Coletânea luso-Brasileira vII

MONSMA, K. Repensando a escolha racional e a teoria da agência: fazendeiros de gado e capatazes no século XIX. Revista Brasileira de Ciências Sociais, [S. 1.], v. 15, n. 43, 2000. Disponível em: <http://www.scielo.br/pdf/rbcsoc/v15n43/006.pdf>. Acesso em: 18 jan. 2016.

NEPOMUCENO, C. Valor para as empresas é um conceito em evolução. Webinsider. 2011. Disponível em: <https://webinsider.com.br/2011/09/12/o-valor-para-as-empresase-um- conceito-em-evolucao/>. Acesso em: 10 de jan. 2016

PESSOA, C. R. M., JAMIL, G. L. Alinhamento estratégico entre a gestão empresarial e o setor de tecnologia da informação: sua observação no momento da aquisição de soluções de tecno- logia. Anais do 7o. Contecsi, 2010.

PESSOA, C.R.M. Gestão da Informação e do Conhecimento no Alinhamento Estratégico em Empresas de Engenharia. Tese de Doutorado apresentada na Universidade Federal de Minas Gerais, 2016.

PESSOA, C.R.M.; NASSIF, M. E.; SILVA, A.M.; MARQUES, M. E. Da gestão de TI à Gestão da Informação e Tecnologia: Uma Abordagem Teórica da Evolução do Conceito. XVII Enancib - Salvador, Bahia, 2016.

PORTER, M. Vantagem competitiva: Criando e sustentando um desempenho superior. Rio de Janeiro: Campus, 1986.

ROCHA, A. In uência da maturidade da Função Sistemas de Informação na Abordagem à Engenharia de Requisitos. 2000. Tese (Doutorado), Universidade do Minho, Braga, 2000. Dis- ponível em: <http://repositorium.sdum.uminho.pt/handle/1822/182>. Acesso em: 13 jan. 2016

Schumpeter, J. A. Teoria do Desenvolvimento Econômico: Uma investigação sobre Lucros, Capital, Crédito, Juro e o Ciclo Econômico. Tradução Maria Silvia Possas, Nova Cultura, São Paulo, 1997

SILVA, A. M. A Informação: Da compreensão do fenómeno e contrução do Objecto Cientí- co. Afrontamento, Porto .Portugal 2006

SILVA, A. M. da; RIBEIRO, F. A gestão da Informação na Administração Pública. Interface, Lisboa, v. 50, n. 161, p. 32-39, nov. 2009.

Silva, D. O. da; Bagno, R. B.; Salermo, M. S. Modelos para gestão da inovação: revisão e análise da literatura. - USP. Production, v. 24, n. 2, p. 477-490, Apr./June 2014

SIMON, H. A. O processo decisório nas organizações. In: PUGH, Derek S.; HICKSON, David J. Os teóricos da organizações. Tradução de Afrânio Carvalho Aguiar et al. Rio de Janeiro: Qualitymark, 2004. p.139-142.

SENRA, N. de C. Regime e política de informação estatística. São Paulo em Perspectiva, São Paulo, v. 16, n. 3, p. 75-85, 2002. Disponível em: $<$ http://www.scielo.br/scielo.php?script $=$ sci_arttext\&pid = S010288392002000300011>. Acesso em: 18 jan. 2016.

Souza, J. C. C.; Barbosa, J. G. P.; Bouzada, M. A. C.; Tavarez, E. Melhores Práticas 
em inovação: Um pesquisa em empresas do setor de TI. ev. Adm. UFSM, Santa Maria, v. 8, número 4, p. 685-705, OUT. - DEZ. 2015

STEINER, G. A.; MINER, J. B. Management Policy and Strategy: Text, Readings, and Cases. New York: McMillan Publishers Inc., 1977.

STRASSMANN, P. A. Information payo : the transformation of work in the electronic age. New York: Free Press, 1985.

TARAPANOFF, K. Informação, Conhecimento e Inteligência em Corporações: Relações e Complementaridade. In: Inteligência, Informação e Conhecimento. Tarapano , K. Ibict, p. 19-36, 2006

Tomaél, M. I.; Alcará, A. R.; Chiara, I. G. di. Das redes sociais a inovação. Ci. Inf., Brasília, v. 34, n. 2, p. 93-104, maio/ago. 2005 